\title{
Sculpture to measure particulate air pollution
}

\author{
R. G. Wakeland \\ New Mexico, USA
}

\begin{abstract}
Make sculpture from laundry detergent bottles, found objects and salvaged construction materials. Particle air pollution collects on white fabric and plastic. This black soot-like discoloration can be compared to particle pollution quantities from USA EPA and other, international websites. K-12 curriculum derives from the sculpture itself and data collection of the particulate air pollution. Contemporary studies in education show that sculpture and visual arts used in teaching encourage reading, writing, and cognitive development.
\end{abstract}

Keywords: sculpture, particle air pollution, particulate air pollution, dust, cognitive development, teaching, reading, writing, literacy, math.

\section{Effect upon nature of $21^{\text {st }}$ century design}

Humans by calculated design and everyday operation of factories, internal combustion engines, and non-renewable energy electric generating stations alter nature. We throw particulates into nature's pristine air. We create designer air. We measure and quantify these particulate concentrations daily on the United States of America (USA) Environmental Protection Agency (EPA) and other web sites. Created from salvaged objects, sculpture measures this particulate air pollution in a graphic, visual way, collecting particulates as black streaks and smudges on textiles and plastic surfaces. The statistics thus take on an inescapable image form. In a public forum, the sculpture confronts us with our degradation of and relationship with nature.

Art, public and private, can be analyzed for its carbon footprint. For example, sculpture composed of salvaged materials preserves air quality compared to sculpture composed of yards and meters, hectares and acres of virgin plastic sheeting and/or solid cast polymer. The lifecycle of the artwork should be factored into its impact upon the environment. Public entities are called upon to 
support sculpture and installations constructed of recycled materials, as well as those described here to measure air pollution in public buildings and landscapes.

\section{Theoretical bases and methods for using art to teach reading, writing, math and cognitive abilities}

Twentieth century studies in the United States of America (USA) have shown visual arts to be effective in teaching language skills and proficiency. Lower achieving students (typically C, D and F students) scored as high as their A-B classmates on recall of visual shapes and content presented in art-appreciation classes taught by volunteers. Primarily large, colorful paintings were used. Art historical, literacy type information was included, such as name, date, and geographical location of the artist. (Epstein and Dauber [2] and Epstein and Salinas [3]).

A qualitative study was conducted at a suburban southern California, USA elementary school using visual arts strategies to teach literacy. It implemented the "Picturing-Writing" curriculum developed at the University of New Hampshire in the 1990s. The authors, two art teachers and one literacy professor, included a literature review summarizing their own and other previous studies. Among the effects of the visual imagery surveyed and studied were motivating students to read and write, a pre-writing composing device, connecting the image with poetry, dialectic response of the artist to the art object of creation, cognitive development, and ideas changing and forming during the creative process. Working on the theory that art is a "'non-linguistic' composing device that assists children in expressing their thoughts", researchers concluded "art plays a critical role as a mediating event for the compositional process" (Andrzejczak et al. [1]).

Researchers in a quantitative study compared reading comprehension in groups of children with various intervention combinations: manipulating the objects described while reading, imagining manipulation objects while reading, reading once and rereading (without any manipulation). Original and previous theory hinged on the language learner's ability to "index" words and phrases to objects or perceptual symbols (toys being manipulated). Indexing is the attachment by the reader of referent, perceptual symbols to words. Therefore, the contribution made by the association of perceptual symbols (the objects being manipulated) to the words being learned/read to accompanying/resulting reading comprehension. The common English as a second language student enigma of flawless verbal reading while comprehending nothing is recognized within first language acquisition: "To the extent that the words are not being indexed, reading becomes a meaningless exercise in word calling" (Glenberg et al. [4]).

Whether via a dump truck in a sand box or a pencil in a cup, the association of the physical world with the text, it is concluded, helps children make inferences to the real world, developmental models and perceptual symbols. Children thus understand not merely the text itself but what the text means. This also contributes to cognitive development (Glenberg et al. [4]). While the toy manipulations are not exactly sculpture apprenticeships, the physical, tactile 
implications for substituting sculpture for the dump truck and sand box are obvious. The vocabulary and concepts could be changed to fit the sculpture. Descriptions of previous studies in the literature encompass any kind of manipulative activity, with drawing being one. Also, visual cues are incorporated into the reported study (Glenberg et al. [4]).

Other emphasis on cognitive development to augment reading is contained in commercially available, packaged curriculum. One internationally taught course incorporates animal picture flash cards, asking for animals' names in verbal responses. It also includes practicing and developing speed in recognizing and naming objects, shapes, and colors. Activities include sorting pictures of common objects into one of three similar, corresponding abstract shapes and reproducing a design with colored shapes after a 10 second view. Incorporating also verbal command/response exercises and other techniques, this method has generally been accepted as successful. The programs tested were Cognition Enhancement Training (COGENT) and PREP. The authors call for continued studies among different demographics (Hayward et al. [5]).

Because this curriculum relies on recycled, used and everyday objects, it can be packaged by educators to send home for a weekend or summer project. Students can bring their finished sculptures, charts, graphs, and drawings back to the school. Or, suffice it to say that the home activity interaction the sculpture fosters is justification alone without the need for return of the sculpture as homework. Even science and math can be taught at home via projects such as this (Lapadat [6]).

\section{The first module}

The first module in this curriculum addresses the arts standard. Teachers and youth group leaders show the images of the sculpture in the appendices, facilitate discussion among students, and then students create their own sculpture.

Name and topic: sculpture to measure particulate air pollution.

Grade/content area and benchmarks, objectives: K-12 arts. Participate in the process of making and looking at works of art

Dates: minimum 2 full days or two weeks, 1 class period per day, or can be expanded. First week/day, students gather recycled materials and found objects and find one example of outdoor sculpture in the neighborhood. Second week/day making a drawing of the proposed sculpture and component parts and assemble it.

Materials and equipment: white fabric; plastic bottles and bottle caps; nylon or jute cord; found objects; clear, translucent or white plastic sheeting or Plexiglas, stapler; hole punch, scissors, washers. Parents, teachers and youth club leaders, as well as high school shop students, can do preliminary deconstruction of found objects, cutting up plastic bottles, and drilling holes.

Grouping and environment: the class listens together as leader/teacher shows images of examples such as in the appendices, and describes the project. Students contribute ideas of how to find materials, found objects, etc. to the group. Teacher facilitates this discussion. Students contribute to the group by 


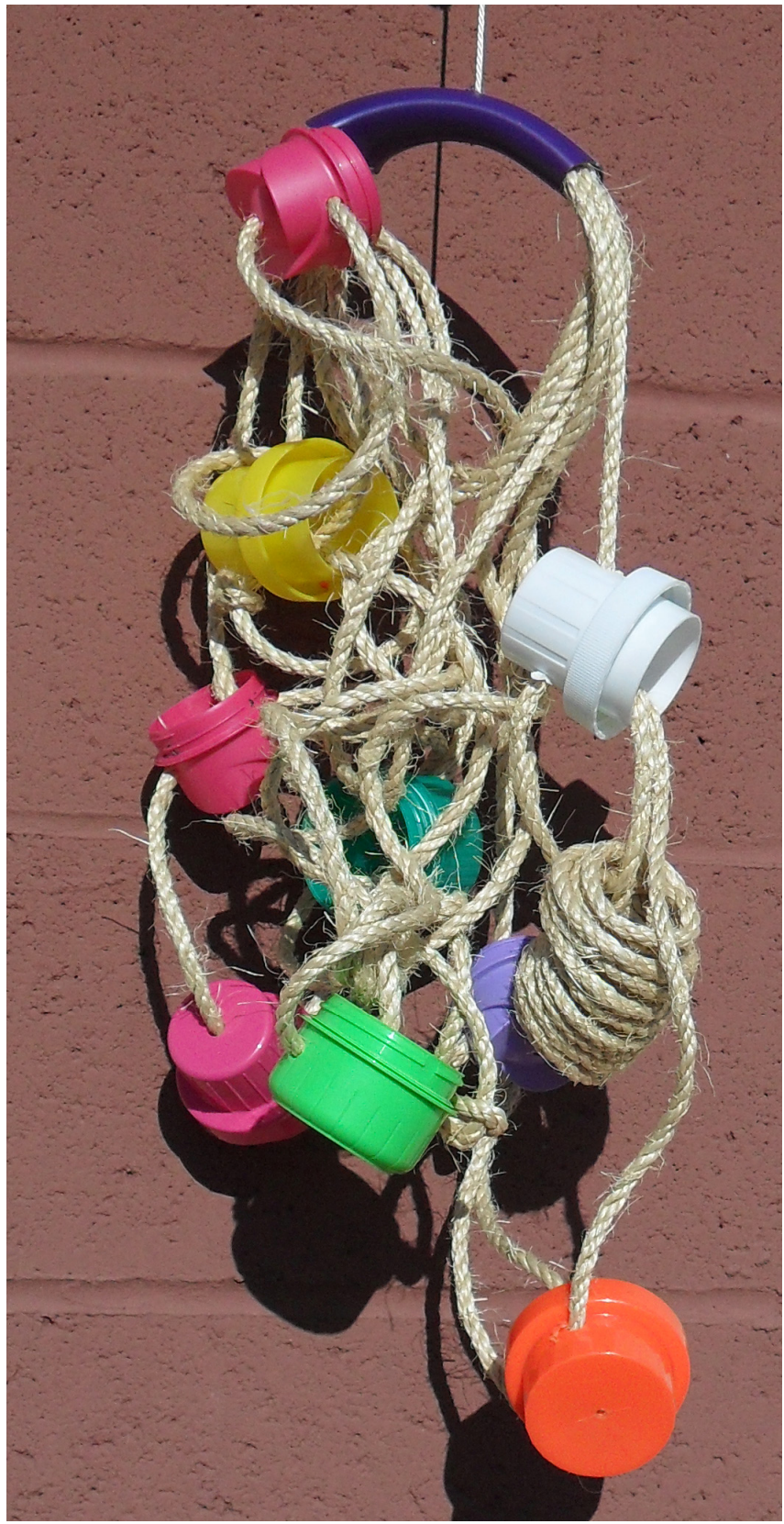

Figure 1: $\quad$ Sculpture to measure air pollution by Robin Gay Wakeland, 2010. Jute (sisal, industrial hemp) and plastic laundry detergent bottle handle and lids. 


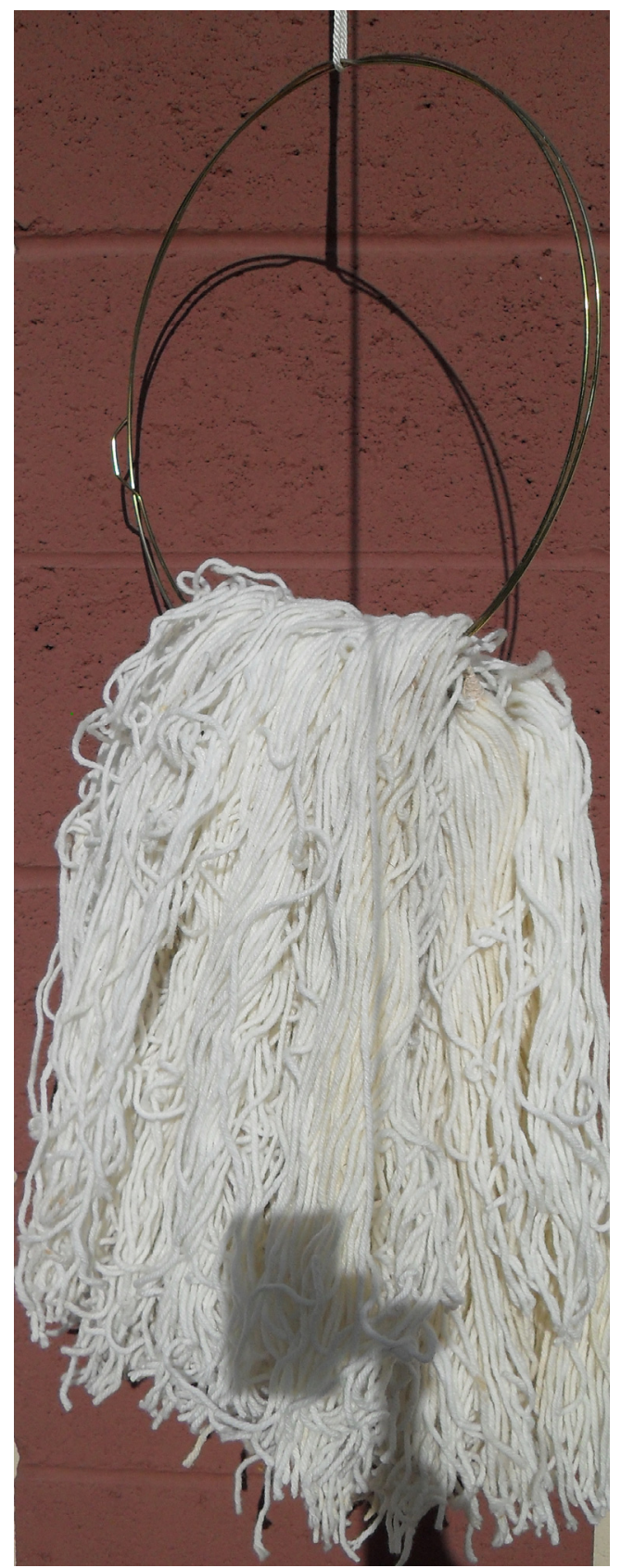

Figure 2: Sculpture to measure particulate air pollution by Robin Gay Wakeland, 2010. Found base metal wire rings, mop from construction materials salvage store, synthetic fibre. 


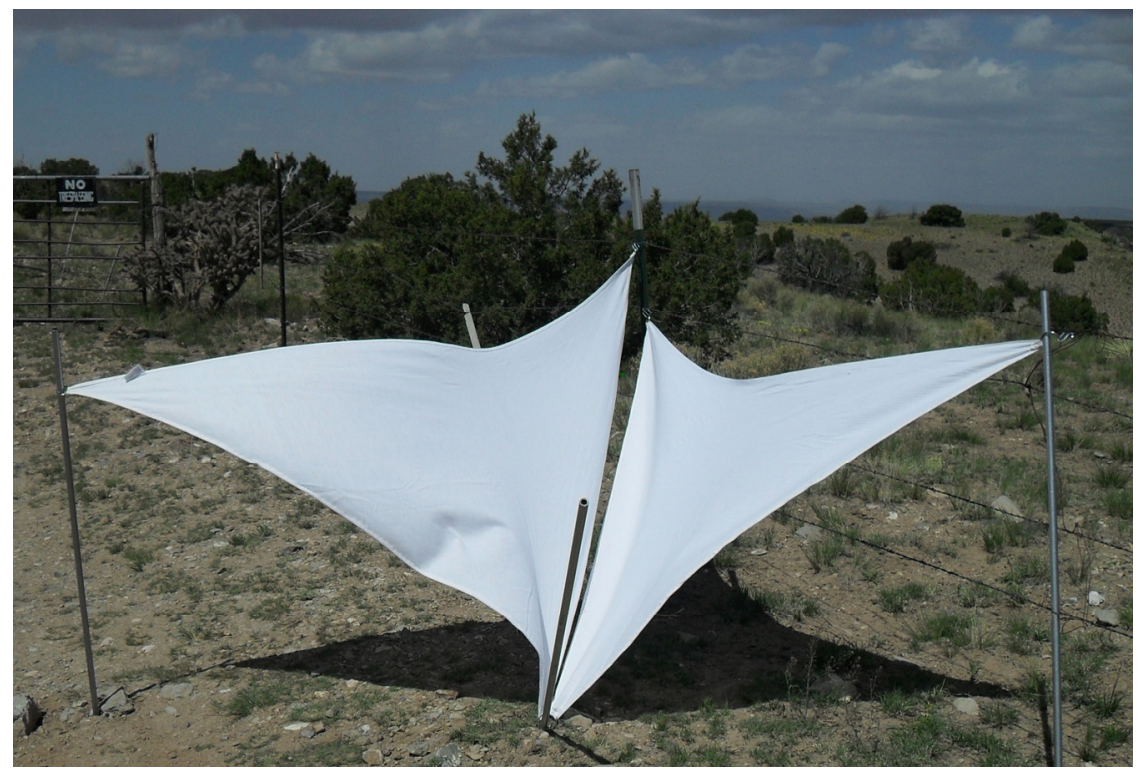

Figure 3: Sculpture to measure particulate air pollution by Robin Gay Wakeland, 2010. Aluminium pipes and key rings borrowed from artist's booth fixtures, in situ fence and thrift store cotton fabric.

describing where they saw an outdoor sculpture nearby. Students work individually on their sculpture. Students present their finished sculpture the group and describe it and where they will install it. Students can take theirsculpture home or install it at the school. One variation is to have the class work together on one larger sculpture. This would be installed at the school, or another public building, indoor or outdoor.

Lesson sequence: teacher/youth group leaders show students the images in appendices as examples. Teacher facilitates discussion about how to collect found objects for the sculpture. Teacher leads discussion about the difference between two- and three-dimensional art. Students are given homework to find an outdoor sculpture in their neighborhood and tell the class about it. Students do drawings of how their sculpture will look and make a list of materials needed and/or components prior to assembly. Students gather materials. Parents, teachers, youth leaders and high school shop students do any drilling and working with sharp/power tools. Students assemble sculpture and describe to class how they made it and where it will be installed.

With a group collaboration, students submit drawings for a large group project. Then the students decide on how to create a group project using ideas from the individual drawings. Teacher facilitates this interaction.

Assessment: Did students grasp the idea of 3-dimensions, or did they create flat objects? Were students able to use a drawing in the creative process to conceptualize, define, and articulate their ideas? Were students able to translate 
their drawing into a 3-D finished project? Were students able to successfully collaborate on a large, single sculpture?

\section{The second module}

The second module focuses on language arts. Students compile visual images of particulate air pollution from various sources including architecture and flags in their neighbourhood. They then create verbal and written reports.

Here is the lesson plan for the language arts standard.

Name and topic: sculpture to measure particulate air pollution.

Grade/content area and benchmarks, objectives: language arts K-12. Locate and use a variety of resources to acquire information across the curriculum.

Dates: can be structured within a variety of time periods.

Materials and equipment: library, computer, internet connection, projector, digital camera (optional), paper and pencil to take notes and make drawings; word processing and slide show software.

Grouping and environment: class listens together as leader/teacher shows sculpture images, describes project and shows USA EPA flash video about particle air pollution. Students go as a group to the library. Students find books individually at library (lower grades: with help from teacher). Students take digital photos or make observations and take notes individually, except younger grades, which go as a group on a field trip to make observations outside. Students work individually on writing up their findings. Students give verbal report to group.

Lesson sequence: teachers/youth group leaders show students the sculpture images and EPA flash video. Students go to the library and find books on air pollution. Teachers help younger students. Higher grades: make annotated bibliography from library sources. Students find visual image of air pollution on internet. Students are given homework to take digital images or make observations (notes and drawings) in situ, on how particle air pollution shows up on outdoor objects (architecture, flags, etc.). This can also be accomplished as a group in a field trip. Teachers can supervise younger students with the use of a digital camera. Students compile these images and include written notes identifying the geographic location of the image, date and time, and other pertinent details. Students also include a one page written summary of their images. Students give a verbal report to the class, showing their images. Older students can produce a slide show or other digital presentation.

Here is the link for the USA EPA website and flash video:

EPA main login page

http://airnow.gov/index.cfm?action=airnow.local

flash movie about particle air pollution on EPA home page

http://www.epa.gov/airnow/pm/pm.html

Assessment: What library and web sources were used for information searches? Quantity and quality of books and images found? How well did older students understand the concept of and complete the annotated bibliography? 
152 Ecosystems and Sustainable Development VIII

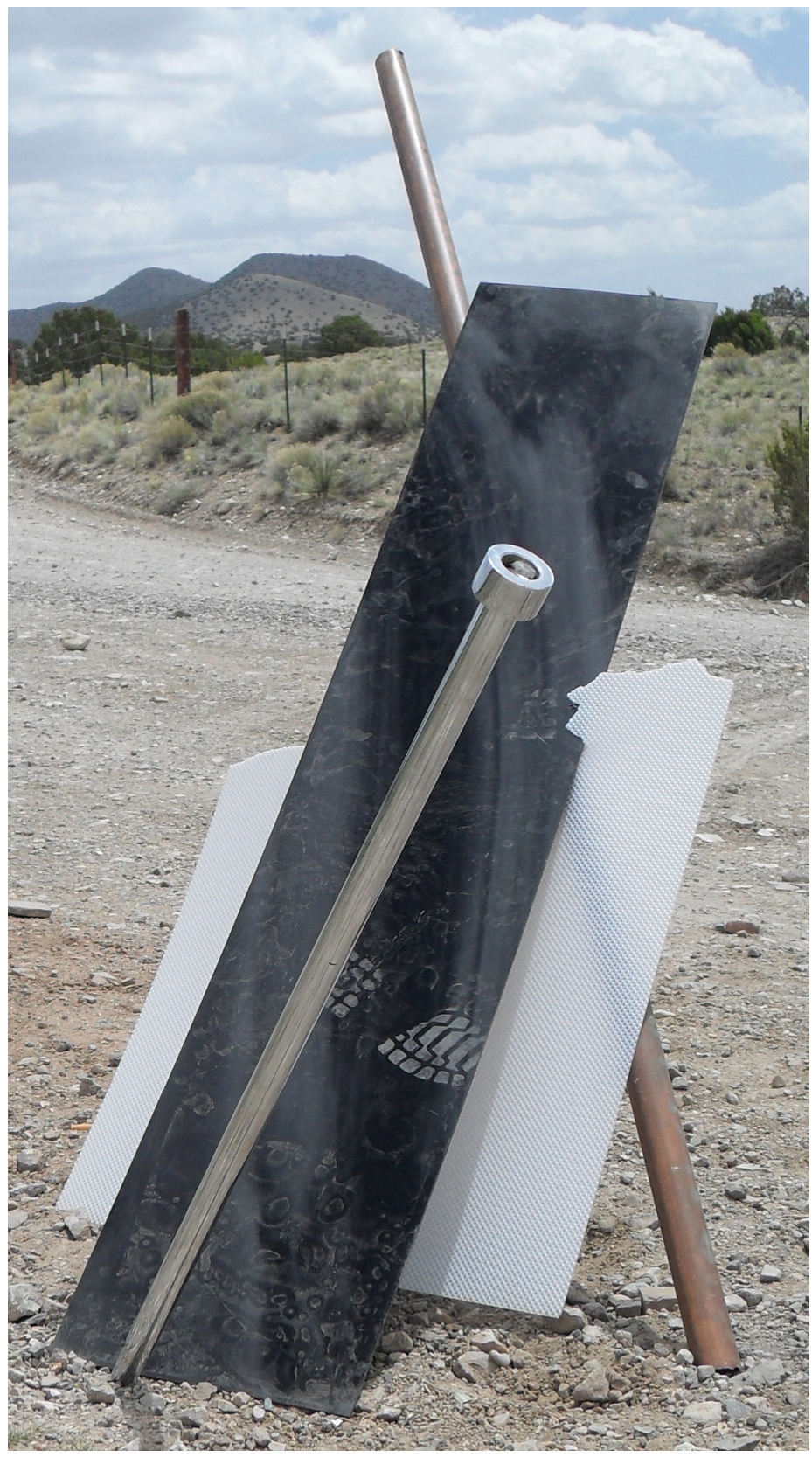

Figure 4: Sculpture to measure particulate air pollution by Robin Gay Wakeland, 2010. Chrome plated steel floor lamp shaft, salvaged copper pipe, Plexiglas and plastic. 
Students' notes, drawings, and digital photos, as well as their written and verbal reports provide summative assessment for language proficiency.

\section{The third module}

The third module teaches the math standards identifying geometrical shapes and charting and graphing information. Students use their own sculpture created in the arts curriculum.

Here is the curriculum plan for the math lessons. Some corporations give support for science and math teaching. See Toshiba America Foundation Math Grants Application Form and Guidelines at

http://www.toshiba.com/tafpub/jsp/recentgrants/712.jsp

Name and topic: sculpture to measure particulate air pollution.

Grade/content area and benchmarks, objectives: K-12 math. Analyze characteristics and properties of two-and three-dimensional geometric shapes. Formulate questions that can be addressed with data and collect, organize, and display relevant data to answer them.

Dates: minimum 2 weeks of regular class time, once a day; longer time span to observe particles collect on the sculpture and track EPA data. First week, students analyze geometrical shapes in the sculpture images, and in their own drawings and sculpture created in the arts lesson. Over time: make observations and/or take digital images of white fabric and plastic/Plexiglas surfaces to record particle air pollution and record EPA particle pollution for the geographical area on spreadsheets.

Materials and equipment: digital camera (optional); computer and access to internet and EPA website; computer spreadsheets software with chart/graphs; examples of 2 and 3 dimensional geometrical objects and shapes; students' finished sculptures and drawings.

Grouping and environment: class listens together as teacher/group leader shows sculpture images and compares geometrical models to the sculpture. Students individually analyze 2-D and 3-D geometric components of their own completed drawings and sculpture, and record particulate air pollution on their sculpture and enter EPA data into spreadsheets.

Lesson sequence: teachers and youth group leaders show images of the appendices and other sculpture created for the purpose, and compare geometric models to the sculpture. If possible, the teacher should obtain digital images of the students' sculpture produced in the arts curriculum and analyze it the same way for the whole class. Students then individually compare their own drawings for their sculpture, as well as the finished sculpture, with geometrical shapes. Over time: students make observations and/or take digital images of white fabric and plastic in their sculptures to record particle air pollution and record EPA particle pollution for the geographical area. Higher grades: plot data from EPA website into spreadsheet and create graphs and charts from it. Compare the particle pollution collecting on sculpture with this data.

Assessment: Have younger students mastered concepts of collecting and compiling data? Have older students mastered computer skills of entering data 
into spreadsheets and creating charts and graphs? Can students recognize twoand three-dimensional geometric shapes in sculpture and their own drawings and sculpture?

\section{Conclusion}

These strands and methods can be adapted to formal school classrooms, summer camps, and after school youth groups. The curriculum can also be packaged as a send-home project for students to complete on the weekends or on vacation. The creativity of the teachers is given free reign. The author and artist hopes teachers and youth group leaders will send their feedback, artwork, suggestions, impressions, and knowledge using this curriculum to her via email: rgwakeland4036@msn.com for inclusion in a study.

\section{References}

[1] Andrzejczak, N., Trainin, G. and Poldberg, M. (2005). From image to text: using images in the writing process. International Journal of Education and the Arts 6(12); http://ijea.asu.edu

[2] Epstein, J.L., and Dauber, S.L (1995). Effects on students of an interdisciplinary program linking social studies, art, and family volunteers in the middle grades. Journal of Early Adolescence. 15, p. 114-144.

[3] Epstein, J.L. and Salinas, K.C. (1991). TIPS social studies and art manual and prototype presentations.Baltimore: Center on Families, Communities, Schools and Children's Learning, Johns Hopkins University.

[4] Glenberg, A.M., Gutierrez, T., Levin, J.R., Japuntich, S., and Kaschak, M.P. (2004). Activity and imagined activity can enhance young children's reading comprehension. Journal of Educational Psychology. 96(3), p. 424-36.

[5] Hayward, D., Das, H., and Janzen, T. (2007). Innovative programs for improvement in reading through cognitive enhancement: A remediation study of Canadian First Nations children. Journal of Learning Disabilities. 40(5), p. 443-57.

[6] Lapadat, M. (1995). How parents can help us teach science. The Hoosier Science Teacher. 21(2):60-63. 